\title{
Short term micro-evolution and PCR-detection of methicillin-resistant and -susceptible Staphylococcus aureus sequence type 398
}

\author{
W. J. B. van Wamel • S. Hansenová Maňásková • \\ A. C. Fluit • H. Verbrugh • A. J. de Neeling • \\ E. van Duijkeren • A. van Belkum
}

Received: 28 August 2009 / Accepted: 2 September 2009 /Published online: 2 October 2009

(C) The Author(s) 2009. This article is published with open access at Springerlink.com

\begin{abstract}
Micro-evolutionary analysis of 70 ST398 isolates by pulsed-field gel electrophoresis (PFGE) using Cfr. $\mathrm{I}$ revealed three sub-clones with abundant inter- and intrasub-clone heterogeneity in spa- and SCCmec-types. In addition, we developed two specific PCRs for the detection of Staphylococcus aureus sequence type 398 (ST 398) isolates with $100 \%$ specificity and high sensitivity.
\end{abstract}

Staphylococcus aureus strains of ST398 are becoming a worldwide threat. ST398 strains are found in human carriers and patients, domestic animals but also in meat products for human consumption [1]. At first it was considered that dissemination of ST398 strains was restricted to animals, especially pigs, and humans working with them

W. J. B. van Wamel · S. Hansenová Maňásková · H. Verbrugh • A. van Belkum

ErasmusMC, University Medical Centre Rotterdam,

Rotterdam, The Netherlands

A. C. Fluit

University Medical Centre Utrecht,

Utrecht, The Netherlands

E. van Duijkeren

University of Utrecht,

Utrecht, The Netherlands

\author{
A. J. de Neeling \\ National Institute for Public Health and the Environment (RIVM), \\ Bilthoven, The Netherlands
}

W. J. B. van Wamel $(\square)$

Department of Medical Microbiology and Infectious Diseases, University Medical Centre Rotterdam,

Room 257b, 's Gravendijkwal 230,

3015 CE Rotterdam, The Netherlands

e-mail: w.vanwamel@erasmusmc.nl only. Recently however, several studies reported the more promiscuous transmission of ST398 among humans [2-4]. Notably, in China ST398 strains are now causing hospitalacquired infections [5]. Since ST398 strains belong to a single multilocus sequence typing (MLST) class, are PFGE non-typeable using $S m a \mathrm{I}$, and have related spa-types, little is known about their micro-epidemiology.

In total, 70 ST398 S. aureus isolates were included in this study, 50 of which were previously spa-typed and analyzed using amplified fragment length polymorphism (AFLP) [6]. Isolates were of clinical origin, but carriage isolates from pigs and humans were also included. The 20 additional ST398 isolates included in our study comprised of seven clinical horse isolates, nine carriage pig isolates obtained from the Veterinary Medical Diagnostic Centre in Utrecht, one strain isolated from the nares of a pig in a slaughterhouse, a cow mastitis isolate and Hong Kong Chinese ST398 strains T-235 and T-252 (courtesy of Dr. M. Ip [7], Prince of Wales Hospital, The Chinese University of Hong Kong). For all new ST398 isolates the presence of mecA and the SCCmec type was defined by polymerase chain reaction (PCR) [8]. All additional ST398 isolates except the cow isolate were methicillin-resistant $S$. aureus (MRSA). Spa-types were determined as described previously [6]. The non-ST398 strains, MRSA of human origin COL (SCCmec I), Mu50 (SCCmec II), N315 (SCCmec II), BK2464 (SCCmec II), ANS46 (SCCmec III), HDE288 (SCCmec IV), MW2 (SCCmec IVa) and WIS (SCCmec V), three MRSA strains isolated from horses and four pig MSSA isolates were included as controls. Spa-typing of these seven non-ST398 animal strains was performed as mentioned above. Finally from our AFLP database [9] 48 randomly chosen representatives of the different AFLP(sub) clusters were included for comparative reasons. 
Table 1 Primers used in this study and ST398 specific polymerase chain reaction (PCR) analyses

\begin{tabular}{|c|c|c|c|c|c|}
\hline Primer set & Sequence & Annealing temperature & Fragment length (bp) & ST398 $n=70(\%)$ & Non ST398 $n=63(\%)$ \\
\hline $\begin{array}{l}\mathrm{A} 04 \mathrm{~F} \\
\mathrm{~A} 04 \mathrm{R}\end{array}$ & $\begin{array}{l}\text { TCATTGCTTGGCGTGTAGGT } \\
\text { TATCAACAGCCGGTGACAAC }\end{array}$ & $58^{\circ} \mathrm{C}$ & 317 & $70(100)$ & $63(100)$ \\
\hline $\begin{array}{l}\text { A07F } \\
\text { A07R }\end{array}$ & $\begin{array}{l}\text { GATCCCAGAATACTTAAATA } \\
\text { TGACCGTAATCTTGTAAATA }\end{array}$ & $50^{\circ} \mathrm{C}$ & 197 & $70(100)$ & $0(0)$ \\
\hline $\begin{array}{l}\mathrm{C} 01 \mathrm{~F} \\
\mathrm{C} 01 \mathrm{R}\end{array}$ & $\begin{array}{l}\text { CATTCATCACACGTATATTC } \\
\text { GGTGATTATTCATGGTTAAG }\end{array}$ & $52^{\circ} \mathrm{C}$ & 140 & $70(100)$ & $0(0)$ \\
\hline $\begin{array}{l}\text { B04F } \\
\text { B04R }\end{array}$ & $\begin{array}{l}\text { GGCAAGATGGCTGGTCACAA } \\
\text { CTGAGAAACTGCGGGTGCAA }\end{array}$ & $60^{\circ} \mathrm{C}$ & 107 & $69(99)$ & $2(3)$ \\
\hline $\begin{array}{l}\text { A10F } \\
\text { A10R }\end{array}$ & $\begin{array}{l}\text { CTAGGCCTGGTTTAATAATA } \\
\text { CAAGTTTCATCGTTTACTTC }\end{array}$ & $52^{\circ} \mathrm{C}$ & 133 & $40(57)$ & $2(3)$ \\
\hline
\end{tabular}

PFGE of all 70 ST398 isolates and ten non ST398 strains (6 MRSA [3 human and 3 horse isolates] and 4 MSSA strains [all pig isolates]) was performed and analyzed using previously described methods [10] except for the use of Cfr9I (a neoschizomer of SmaI) to digest the chromosomal DNA. Banding patterns were interpreted by two independent persons using GelCompar software (Applied Maths NV, Sint-Martens-Latem, Belgium).

In an approach to develop an ST398 specific PCR, four ST398-specific DNA sequences previously obtained from AFLP analyses were studied [6]. Using the genomic sequence of S0385 (ST398) [11] we found that fragments A07, A10 and C01 have a 100\% match with the DNA sequence of S0385, but not with any of the other 13 sequenced $S$. aureus strains present in the database (www. ncbi.nlm.nih.gov/blast). Besides a 100\% identity with S0385, also B04 showed a 100\% match with the 3 'end of SAB0857 and the 5'end of SAB0858 of the bovine strain RF122 [12]. PCR primers were developed for A07, A10, C01, B04 and a positive control A04 (an AFLP fragment available in all $S$. aureus strains). PCRs were performed using the following protocol: $1 \mathrm{~min}$ at $94^{\circ} \mathrm{C}, 1 \mathrm{~min}$ at the specific annealing temperature and $1 \mathrm{~min}$ at $72^{\circ} \mathrm{C}$; this sequence was repeated 25 times (Table 1).
When performing PCRs with primer sets A07 and C01 all 70 ST398 isolates were positive, but all 63 non-ST398 isolates were negative (Table 1). Primer set A10 was positive in only $57 \%$ of all ST398 isolates, while B04 was positive in $99 \%$ of the ST398 isolates but also in 3\% of the non-ST398 isolates.

As expected, all spa-types of the ST398 isolates were related though among the pig and horse isolates of the additional collection three relatively obscure $s p a$-types were identified: t899, t1939 and t2123 (Table 2). In the nonST398 isolates unrelated spa-types were found more frequently. The three MRSA isolates from horses had spatype t064, two pig isolates displayed t337, and two pig isolates were characterized as $\mathrm{t} 3427$. The Cfr. $9 \mathrm{I}$ and SmaI digestion patterns of non-ST398 strains were identical (data not shown). The previous AFLP analyses alike [6], PFGE data clearly show that ST398 isolates form a distinct lineage (Fig. 1). However, on the basis of our results the ST398 stains can be divided into three different clusters: A, $\mathrm{B}$, and $\mathrm{C}$, with $\mathrm{A}$ being most abundant. In clusters $\mathrm{A}$ and $\mathrm{B}$, six and two sub clusters can be determined, respectively. In isolates from cluster $\mathrm{C}$ and the sub clusters of $\mathrm{A}$ and $\mathrm{B}$, in more or in lesser extent, a dominant spa-type was found. Associations were also found between SCCmec type or its absence and PFGE patterns. The most prominent examples
Table 2 spa-types of the ST398 isolates in this study

\footnotetext{
${ }^{a}$ Repeat differing in one base from repeat 8

b Repeat differing in two bases from repeat 25
}

\begin{tabular}{|c|c|c|c|c|c|c|c|c|c|c|}
\hline \multirow{2}{*}{$\frac{s p a \text {-type }}{\text { t2123 }}$} & \multicolumn{10}{|c|}{ Repeats } \\
\hline & 08 & & & 25 & & & & & & \\
\hline $\mathrm{t} 1255$ & 08 & 16 & & & & & 34 & & 24 & 25 \\
\hline $\mathrm{t} 567$ & 08 & & 02 & 25 & & & & & 24 & 25 \\
\hline $\mathrm{t} 108$ & 08 & 16 & 02 & 25 & & & & & 24 & 25 \\
\hline $\mathrm{t} 1254$ & $106^{\mathrm{a}}$ & 16 & 02 & 25 & & & 34 & & 24 & 25 \\
\hline t011 & 08 & 16 & 02 & 25 & & & 34 & & 24 & 25 \\
\hline $\mathrm{t} 571$ & 08 & 16 & 02 & 25 & 02 & 25 & 34 & & & 25 \\
\hline t034 & 08 & 16 & 02 & 25 & 02 & 25 & 34 & & 24 & 25 \\
\hline t898 & 08 & 16 & 02 & 25 & 02 & 25 & 34 & 34 & 24 & 25 \\
\hline t899 & $07^{\mathrm{a}}$ & 16 & & $23^{\mathrm{b}}$ & 02 & & 34 & & & \\
\hline t1939 & $07^{\mathrm{a}}$ & & & $23^{\mathrm{b}}$ & 02 & & 34 & & & \\
\hline
\end{tabular}




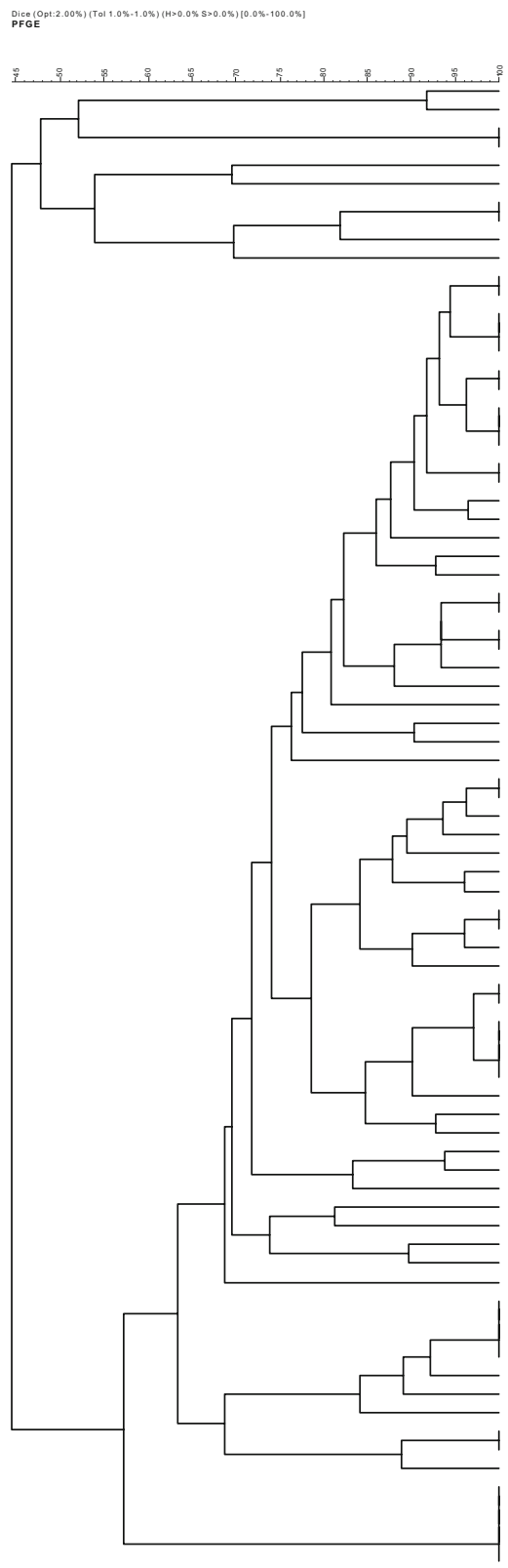

PFGE
I II

III

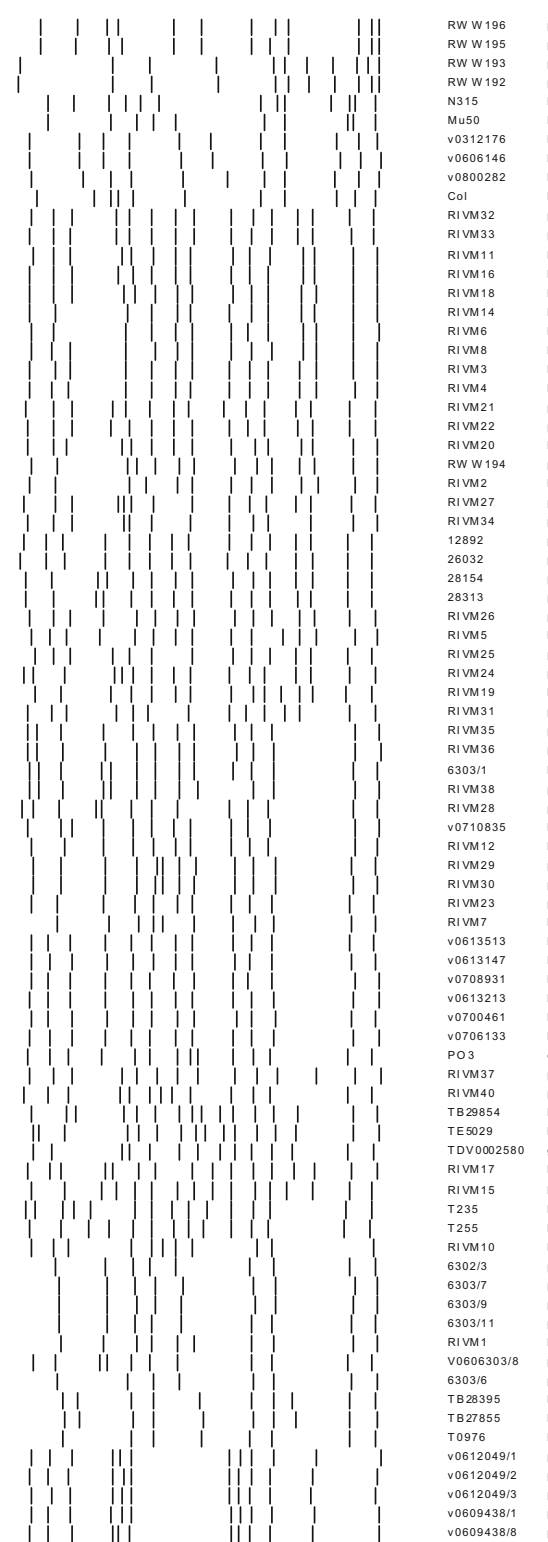

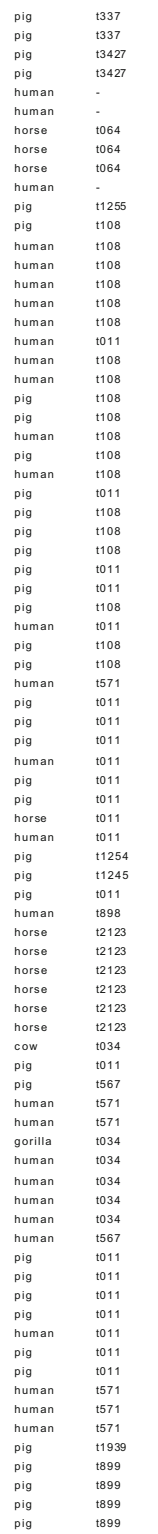

$$
\begin{aligned}
& \begin{array}{l}
01-200 \\
01-200
\end{array}
\end{aligned}
$$

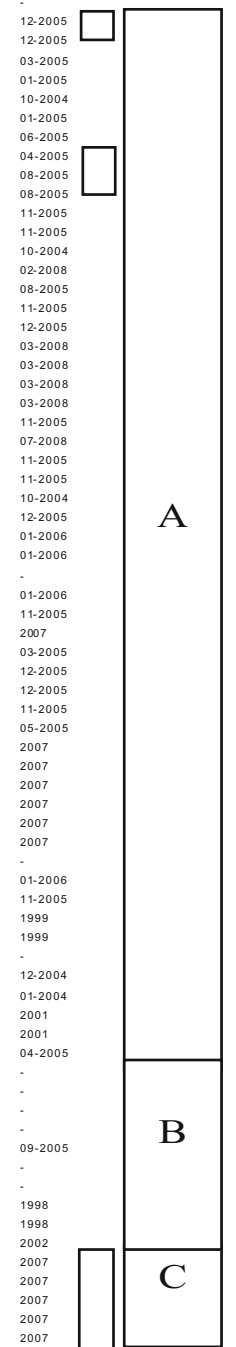$$
\begin{aligned}
& 01-2008 \\
& 01-2008 \\
& 01-2008
\end{aligned}
$$$$
\text { va }
$$$$
\text { iva }
$$$$
\text { va }
$$

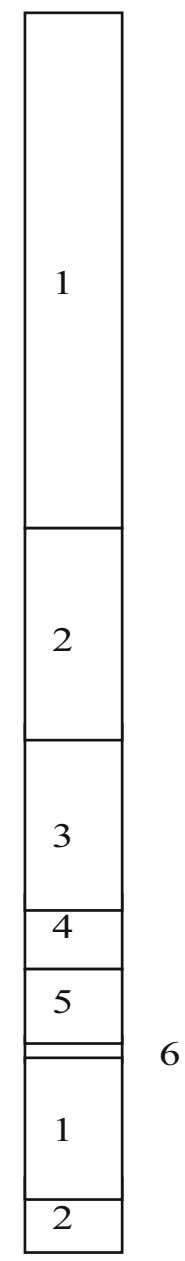

Fig. 1 Dendrogram of the PFGE data from ten non ST398 and 70 ST398 isolates. Next to the dendrogram, the PFGE of Cfr9I macrorestriction fragments, strain name, host, spa-type, SCCmec-type, isolation date and
PFGE-type are given. The boxes indicated with I, II and III represent isolates with a similar PFGE banding pattern but with different spatypes, PFGE clusters, and PFGE sub clusters, respectively are cluster $\mathrm{C}$ and sub cluster A1 harboring only $\mathrm{SCCmec} \mathrm{V}$ and sub cluster B2 isolates being negative for SCCmec (Fig. 1). The sub division of sub cluster A1 is presumably the result of the presence of a $C$ froI restriction site in SCCmec $\mathrm{V}$. In case of cluster $\mathrm{C}$ this is probably of lesser consequence for the digestion patterns are very different from clusters A and $\mathrm{B}$. These data indicate that isolates from PFGE-cluster A belong to a successful ST398 clade, that can either diversify rapidly or are members of older clones that diversified more slowly. In the different branches of this cluster different SCCmec were introduced, so did repeat deletions, duplica- tion and/or base modifications in the variable region of spa. This degree of variation might be the result of a random process or differences due to selective immunological pressure in the different hosts from which PFGE-cluster A isolates were obtained. This raises the question whether spatyping can be used for monitoring the epidemiology of ST398 isolates. Although a predominant spa-type was found in PFGE clusters $\mathrm{C}$ and the different sub clusters of $\mathrm{A}$ and $\mathrm{B}$, in several isolates with an identical PFGE profile spa-types were different (Fig. 1). Another problem is the fact that two spa-types, t011 and t571, were found in both PFGE-clusters 
A and B. So, in these lineages either spa did not diversify or this is the result of homoplasia. On the other hand, all isolates from the distinct PFGE-cluster $\mathrm{C}$ (isolated from pigs at the same farm) carried one of two obscure but close related ST398 spa-types. This indicates that spa-types can predict genetic background in ST398. Finally, no clear relation between PFGE clusters and hosts was found.

In conclusion, we developed two ST398-specific PCRs for detection of $S$. aureus ST398. Such rapid, powerful and convenient diagnostic tools are important in clinical settings but also for monitoring colonization of individuals involved in pig farming or other forms of livestock handling. Also for those involved in quality control of food products these tests are an important commodity. PFGE using Cfr 9 I can be used to type ST398 isolates; this identifies three major genotypes. Although among PFGE-cluster $\mathrm{C}$ and the different sub clusters A and B dominant spa-types were found, spa typing is not a robust indicator of genetic background in ST398, in particular for $\mathrm{t} 011$ and $\mathrm{t} 571$. Based on our data we feel that the evolution of the ST398 genome as a whole proceeds at a different pace than the ST398 spa gene does.

Open Access This article is distributed under the terms of the Creative Commons Attribution Noncommercial License which permits any noncommercial use, distribution, and reproduction in any medium, provided the original author(s) and source are credited.

\section{References}

1. van Loo IH, Diederen BM, Savelkoul PH, Woudenberg JH, Roosendaal R, van Belkum A et al (2007) Methicillin-resistant Staphylococcus aureus in meat products, the Netherlands. Emerg Infect Dis 13(11):1753-1755
2. Welinder-Olsson C, Floren-Johansson K, Larsson L, Oberg S, Karlsson L, Ahren C (2008) Infection with Panton-Valentine leukocidin-positive methicillin-resistant Staphylococcus aureus t034. Emerg Infect Dis 14(8):1271-1272

3. Wulf MW, Markestein A, van der Linden FT, Voss A, Klaassen C, Verduin CM (2008) First outbreak of methicillin-resistant Staphylococcus aureus ST398 in a Dutch hospital, June 2007. Euro Surveill 28(9):13

4. Voss A, Loeffen F, Bakker J, Klaassen C, Wulf M (2005) Methicillin-resistant Staphylococcus aureus in pig farming. Emerg Infect Dis 11(12):1965-1966

5. Yu F, Chen Z, Liu C, Zhang X, Lin X, Chi S et al (2008) Prevalence of Staphylococcus aureus carrying Panton-Valentine leukocidin genes among isolates from hospitalised patients in China. Clin Microbiol Infect 14(4):381-384

6. van Belkum A, Melles DC, Peeters JK, van Leeuwen WB, van Duijkeren E, Huijsdens XW et al (2008) Methicillin-resistant and susceptible Staphylococcus aureus sequence type 398 in pigs and humans. Emerg Infect Dis 14(3):479-483

7. Ip M, Yung RW, Ng TK, Luk WK, Tse C, Hung P et al (2005) Contemporary methicillin-resistant Staphylococcus aureus clones in Hong Kong. J Clin Microbiol 43(10):5069- 5073

8. Boye K, Bartels MD, Andersen IS, Moller JA, Westh H (2007) A new multiplex PCR for easy screening of methicillin-resistant Staphylococcus aureus SCCmec types I-V. Clin Microbiol Infect 13(7):725-727

9. Melles DC, Tenover FC, Kuehnert MJ, Witsenboer H, Peeters JK, Verbrugh HA et al (2008) Overlapping population structures of nasal isolates of Staphylococcus aureus from healthy Dutch and American individuals. J Clin Microbiol 46(1):235-241

10. Lebon A, Labout JA, Verbrugh HA, Jaddoe VW, Hofman A, van Wamel W et al (2008) Dynamics and determinants of Staphylococcus aureus carriage in infancy: the Generation R Study. J Clin Microbiol 46(10):3517-3521

11. Schijffelen MJ, Boel CHE, van Strijp JAG, Fluit AC (2009) Whole genome analysis of a pig-associated methicillin-resistant Staphylococcus aureus ST398 isolate from a case of human endocarditis (in press)

12. Herron-Olson L, Fitzgerald JR, Musser JM, Kapur V (2007) Molecular correlates of host specialization in Staphylococcus aureus. PLoS ONE 2(10):e1120 